Article

\title{
The Impacts of Atmospheric Moisture Transportation on Warm Sector Torrential Rains over South China
}

\author{
Shuixin Zhong * and Zitong Chen \\ Institute of Tropical and Marine Meteorology/Guangdong Provincial Key Laboratory of Regional Numerical \\ Weather Prediction, China Meteorological Administration, No.312 Dongguanzhuang Road, Tianhe, \\ Guangzhou 510507, China; ztchen@grmc.gov.cn \\ * Correspondence: sxzhong@grmc.gov.cn; Tel.: +86-020-3945-6461
}

Received: 7 June 2017; Accepted: 27 June 2017; Published: 30 June 2017

\begin{abstract}
Warm Sector Torrential Rains (WSTRs) occurring during the outbreak of the monsoon in May of 2015 in South China were studied using surface automatic weather observational data, sounding, European Centre for Medium-Range Weather Forecasts Reanalysis interim Data (ERA-interim), satellite and radar data, and a four-level nested grid simulation with the finest grid spacing of $1 \mathrm{~km}$ using the Weather Research and Forecasting model (WRF). The results show that the extreme precipitation event, which had maximum rainfall amounts of $406.3 \mathrm{~mm}$ in $10 \mathrm{~h}$ and $542.2 \mathrm{~mm}$ in $24 \mathrm{~h}$ on 20 May 2015, and was characterized by its rapid development and its highly concentrated and long duration of heavy rainfall, occurred over the trumpet-shaped topography of Haifeng. The simulation results indicated that the South China Sea (SCS) atmospheric moisture transportation (AMT) was crucial in triggering the precipitation of the WSTR over South China. The simulation of the WSTR was conducted by using the total energy-mass flux scheme (TEMF), which provided a reasonable simulation of the circulation and the vertical profile in the Planetary Boundary Layer (PBL) as well as the estimation of the precipitation. The AMT, which extends from the Beibu Gulf and the South China Sea to the coastal areas and provides Shanwei with a considerable amount of moisture in the boundary layer, and the effects within the PBL, which include orographic effects, an extra low-level jet, and a high-energy tongue characterized by a high-potential pseudo-equivalent temperature tongue with a warm and moist southwesterly wind, were the important large-scale factors causing the WSTR.
\end{abstract}

Keywords: warm sector; topography; boundary layer; low-level jet

\section{Introduction}

Warm Sector Torrential Rains (WSTRs) are one of the most important weather systems involved in the flood seasons over South China. WSTRs usually occur in a warm zone either with a surface front in the north or without a front over southern China (Figure 1). They are characterized by short-duration heavy rainfall and high concentrations over mountainous areas, as well as their sudden and disastrous appearances in South China. Observation experiments in the late 1970s confirmed that WSTRs account for the primary torrential rains during the flood season over South China [1]. Owing to the influences of the Westerlies and tropical weather systems as well as the dynamic and thermodynamic impacts of the complex underlying surface, WSTRs cause difficulties in daily forecasting operations during the flood seasons in South China.

The physical processes in the planetary boundary layer (PBL) play an important role in the formation of torrential rains during flood seasons in South China; these processes include the influence of the low-level jet (LLJ), topographic effects, and the effects of the distribution of the land and sea [2]. Because there is no significant uplift effect from the large-scale weather system, the triggering mechanism of the WSTRs is often associated with mesoscale processes and the impacts of the complex 
underlying surface within the PBL. WSTRs caused by the easterly reflux, especially the strong southwest monsoon burst, are directly influenced by low-level processes in the PBL [3]. WSTRs could be triggered by other mesoscale processes within the PBL caused by the mesoscale convective system (e.g., [4-6]) and the mesoscale vortex [7-9], as well as orographic effects [10-12].

Numerical evaluations show that the different PBL schemes in mesoscale models have a large effect on the performance when simulating boundary layer structures (e.g., [13-15]). Sensitivity experiments show that nonlocal mixing is necessary to more accurately forecast lower-tropospheric lapse rates within the warm sector of severe weather environments [16]. Small-scale properties within the PBL have a significant influence on the resolved scale owing to the complex nonlinear nature of the atmosphere (e.g., boundary layer turbulence and gravity wave drag). For the convective PBL, it is important to parameterize the vertical turbulent fluxes and the subgrid-scale condensation in a realistic manner. Mielikainen [17] proposed a PBL parameterization scheme based on the total energy-mass flux (TEMF) that unifies the turbulence and moist convection components; his scheme showed a more optimized performance than that of other PBL schemes.

The previous studies showed that the atmospheric moisture transportation (AMT) was another essential impact factor of the continental precipitation. Gimeno et al. [18] identified the sources of atmospheric moisture by using the analytical models and water vapor tracers methods. The results showed that the ocean provide atmospheric moisture to the continental precipitation. For instance, the subtropical northern Atlantic Ocean provided moisture for precipitation to the largest continental area, extending from Mexico to parts of Eurasia, and even to the South American continent during the Northern Hemisphere winter. Drumond et al. [19] identifies the climatological moisture sources for different regions in China through a Lagrangian methodology. The results suggested that the contributions of moisture from the East and South China Seas are significant for precipitation in the eastern and southeastern coastal areas. The LLJ, is recognized as the major conveyor of low-level moisture transport $[20,21]$. The contribution of the LLJ to low-level moisture transport over the central plains is almost $50 \%$ above average non-LLJ values [22].

In this study, we investigate the performance of The Weather Research and Forecasting (WRF) Model and evaluate the ability of the TEMF scheme by simulating a typical WSTR case over South China. The effects of the atmospheric moisture transportation are examined. Multi observational data are used to evaluate the simulation results on the torrential rain event that occurred in the coastal areas of eastern Guangdong during the morning of 20 May 2015, including satellite measurements of the cloud top brightness temperature (TBB), combined radar reflectivity, automatic weather station observation data, and sounding data. An overview of the synoptic scale weather system and related torrential rains is given in Section 2, a model description and the experimental setup are provided in Section 3, the results are analyzed in Section 4, and the discussion and conclusions are stated in Section 5.

\section{Overview}

The torrential rain event that occurred in the coastal areas of eastern Guangdong during the morning of 20 May 2015, particularly over Shanwei and its adjacent regions, was affected by both the orographic effects in the north and the oceanic effects in the south. Shanwei is located in front of a trumpet-shaped topography with Lianhua Mountain in the northwest and Emei Zhang Mountain in the north (Figure 1). The 24-h accumulated rainfall of ten stations over the relevant areas reached more than $400 \mathrm{~mm}$, and one station (G1827) recorded $542.2 \mathrm{~mm}$. The distribution of the torrential rains was consistent with the topography, and the rainfall amounts at the stations in the warm-sector areas were much heavier than those observed over the northern mountainous areas. Figure 2 shows that the major periods of precipitation were concentrated in the early morning. Records from Haifeng station, one of the meteorological stations in China, showed that the maximum hourly rainfall reached $64.6 \mathrm{~mm}$ at 0200 UTC (Universal Time) on 20 May and that the hourly rainfall from 2100 UTC 19 May to 0600 UTC 20 May exceeded $20 \mathrm{~mm}$, with a rainfall amount of $406.3 \mathrm{~mm}$ in $10 \mathrm{~h}$. The other three automatic weather stations in Figure 2 all recorded maximum hourly rainfall exceeding $60 \mathrm{~mm}$, 
especially station G1827; the event was characterized by its long duration of heavy rainfall with $13 \mathrm{~h}$ of hourly rainfall exceeding $20 \mathrm{~mm}$. Figure 2 also shows that the surface temperature increased during the daytime before the occurrence of heavy rainfall and reached $34{ }^{\circ} \mathrm{C}$ at 1100 UTC on 19 May at station G1827. The horizontal wind evolution indicates that a southerly wind existed prior to the occurrence of the rainfall. The torrential rains in this case showed rapid development, high concentration, and extreme precipitation.

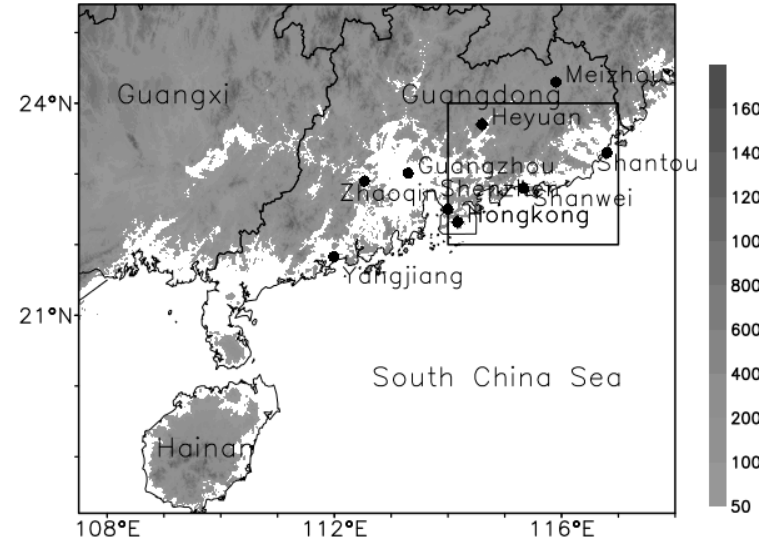

(A)

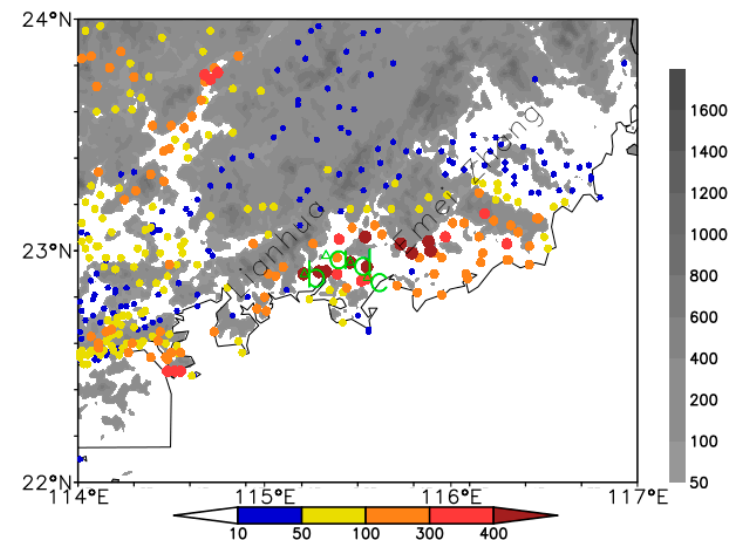

(B)

Figure 1. (A) Topography (shading) over South China, the rectangle represents the zoomed area in figure b; the dots represent the radar stations. (B) The 24-h accumulated rainfall at 1200 UTC on 20 May 2015. The character a, b, c and d next to the green triangle represent Haifeng, G1803, G1827 and G1847 in Figure 2.

The hourly distribution of the TBB and precipitation in Figure 3 indicates that the strongest precipitation over Shanwei was primarily concentrated between 2000 UTC 19 May and 0400 UTC 20 May. The rainfall area was stationary over Shanwei, and the northwest rain belt was moving southward in this case. The rainfall intensity showed a good corresponding relationship with the TBB. It is interesting that the TBBs in Guangxi Province and in the middle of Guangdong were lower than that in the Shanwei area during the rainfall. The TBB at Shanwei was between $-70{ }^{\circ} \mathrm{C}$ and $-60{ }^{\circ} \mathrm{C}$, whereas the TBB over the northwest reached $-80{ }^{\circ} \mathrm{C}$ and even lower, which indicates that the convective height over Shanwei was relatively lower than that of the systematic rainfall over the northwest. This is likely related to shallow convection within the PBL [13]. Hourly radar composite images of the distribution of strong radar reflectivity over Shanwei correlated well with the distribution of topography, the city being located south of Lianhua Mountain (not shown). Both radar and satellite data showed that the heavy rainfall over Shanwei occurred throughout the entire lifetime of the convective system in the northwest. The intensity of the radar reflectivity over Shanwei reached more than 35 DBZ, with a maximum of more than 50 DBZ from 2200 UTC 19 May to 0200 UTC 20 May. The synoptic environment and experimental setup and the simulation results are discussed in Sections 3 and 4 , respectively. 


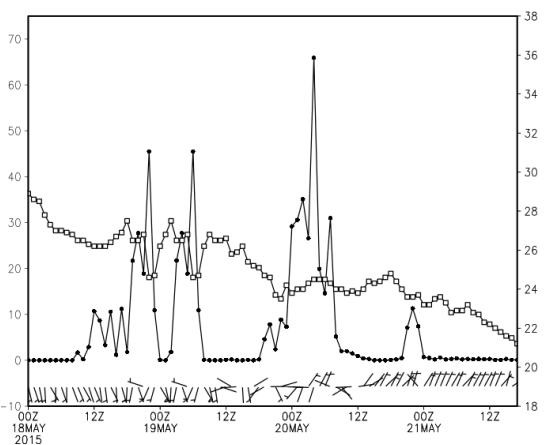

(a)

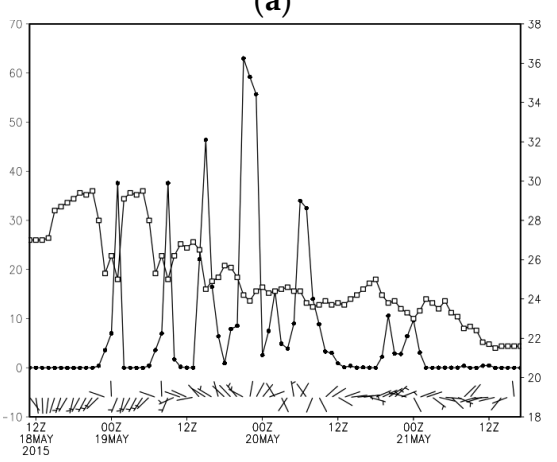

(c)

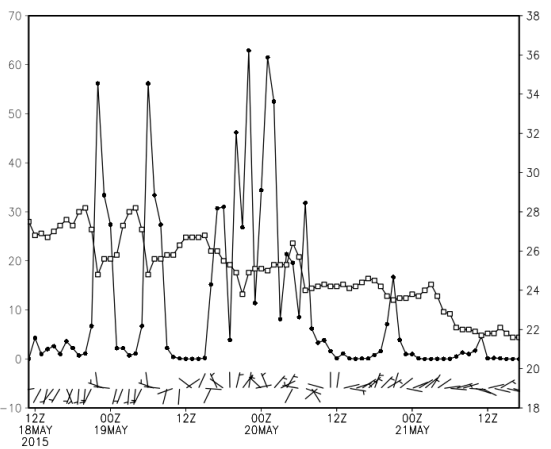

(b)

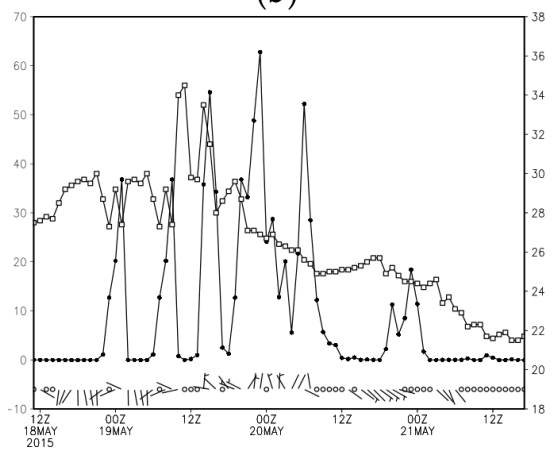

(d)

Figure 2. Time series of the hourly precipitation, temperature, and horizontal wind at four weather stations in the WSTR: (a) Haifeng, (b) G1803, (c) G1827, and (d) G1847. The line with empty squares represents the temperature, and the line with filled dots represents the precipitation.

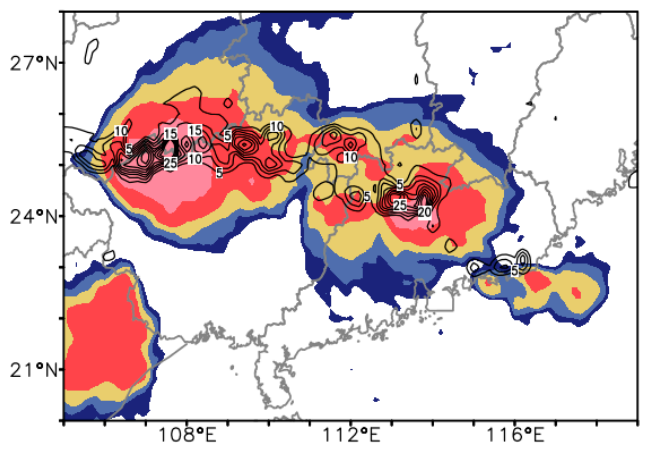

(a)

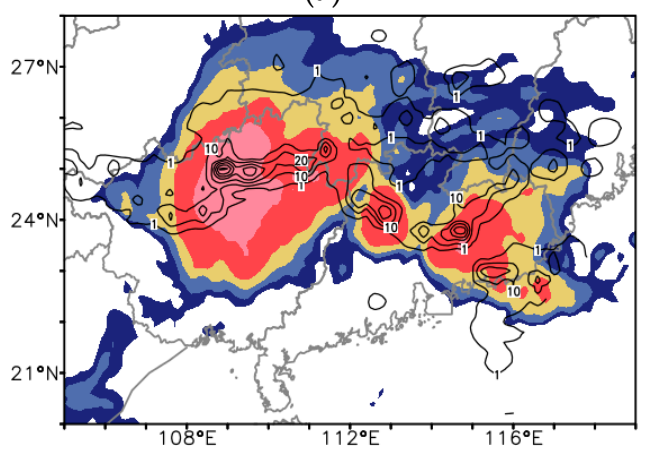

(c)

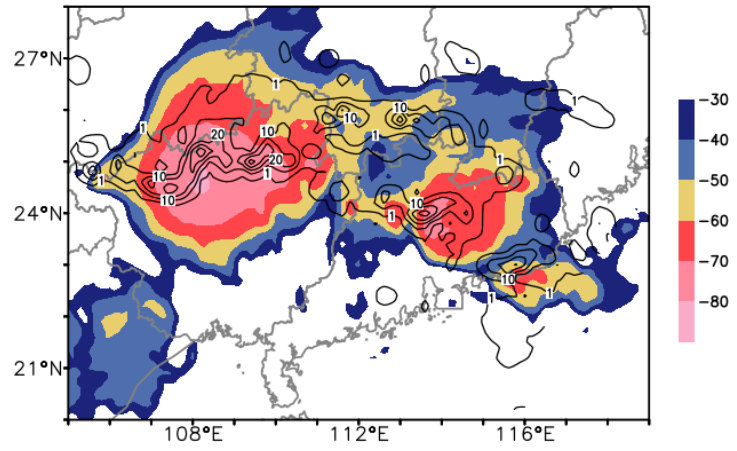

(b)

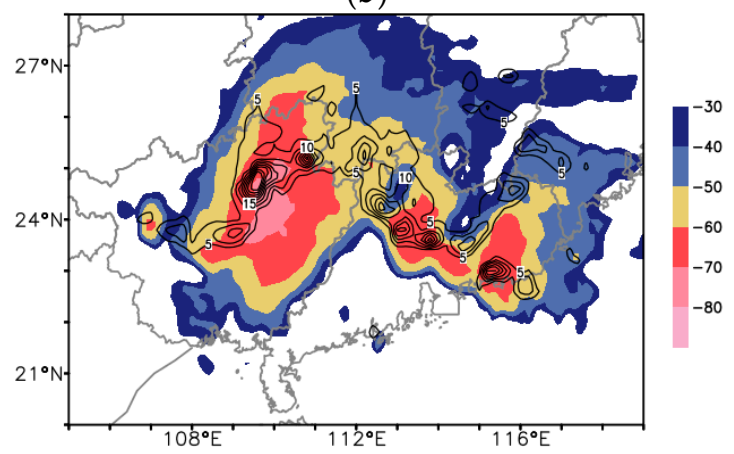

(d)

Figure 3. Cont. 


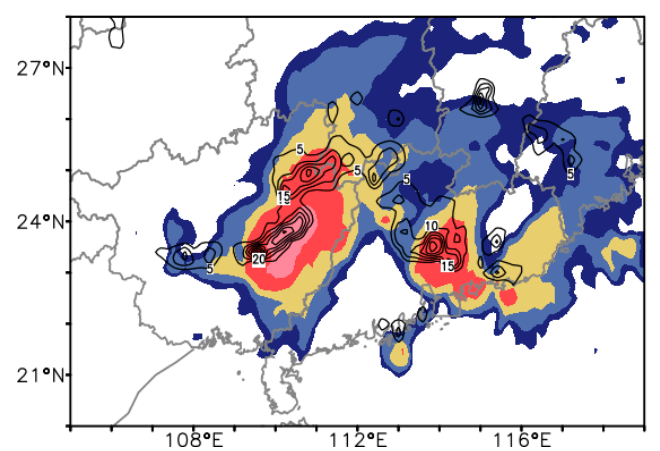

(e)

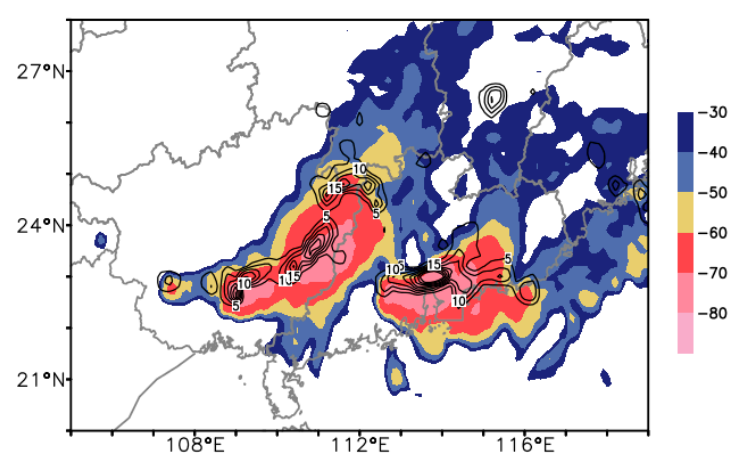

(f)

Figure 3. Hourly distribution of precipitation and TBB less than $-30{ }^{\circ} \mathrm{C}$ derived from China's FY-geostationary satellite at (a) 1900 UTC, (b) 2100, (c) 2300 UTC 19 May, (d) 0100, (e) 0300 and (f) 0500 UTC 20 May in 2-h intervals; the lines represent the precipitation, and the shaded regions represent the $\operatorname{TBB}\left({ }^{\circ} \mathrm{C}\right)$.

\section{Methodology}

In this study, we performed a suite of simulations using the nonhydrostatic mesoscale model WRF-ARW, version 3.6.0 ([23], NCAR, Boulder, CO, USA). The model was initialized at 1200 UTC on 19 May 2015, using the National Centers for Environmental Prediction (NCEP) FNL $1^{\circ} \times 1^{\circ}$ analysis data. The model physics include a shortwave cloud-radiation interaction scheme [24], a rapid radiative transfer model long wave scheme [25], a WRF single-moment six-class scheme [26], the Kain-Fritsch cumulus scheme $[27,28]$ for the outer two domains, and a TEMF scheme [29] for the surface layer and PBL parameterization.

The TEMF parameterization was developed on the basis of the eddy diffusivity-mass flux scheme [30] by considering the vertical mixing effects of the mass flux and eddy diffusivity calculated from the total turbulent energy via the sum of the turbulent kinetic energy and the turbulent potential energy. The TEMF scheme provides a more realistic profile for the shallow cumulus conditions than traditional boundary layer schemes with more entrainment of the dry, warm air from above the boundary layer, which is important during the early development of the convective boundary layer [31]. The governing equation for the vertical flux of a variable $\Psi$ in the mass flux and diffusion framework in TEMF is

$$
\overline{w^{\prime} \psi^{\prime}}=-K \frac{\partial \psi}{\partial z}+M\left(\psi_{u}-\psi\right)
$$

where $\Psi$ can be the liquid water potential temperature $\left(\theta_{i}\right)$, total water specific humidity $\left(q_{t}\right)$, wind components $(\mathrm{u}, \mathrm{v})$, or the total turbulent energy $(E)$. Here $K$ and $M$ are the eddy diffusivity and mass flux as indicated in Equation (1). The subscript denotes the updraft properties, and the unsubscripted variables are the properties of the environment.

Figure 4 shows the four nested model domains using the Lambert map projection; the domains have $(x, y)$ dimensions of $167 \times 107(\mathrm{D} 1), 244 \times 157(\mathrm{D} 2), 274 \times 214(\mathrm{D} 3)$, and $424 \times 337(\mathrm{D} 4)$ with grid sizes of $27,9,3$, and $1 \mathrm{~km}$, respectively. The outermost mesh (D1) covers a large domain size and includes most of East Asia. The second domain (D2) covers South China, and the third domain (D3) covers most of Guangdong Province. The finest mesh (D4) covers the distribution of the mesoscale convective systems during the evolution of the convection over Shanwei. 


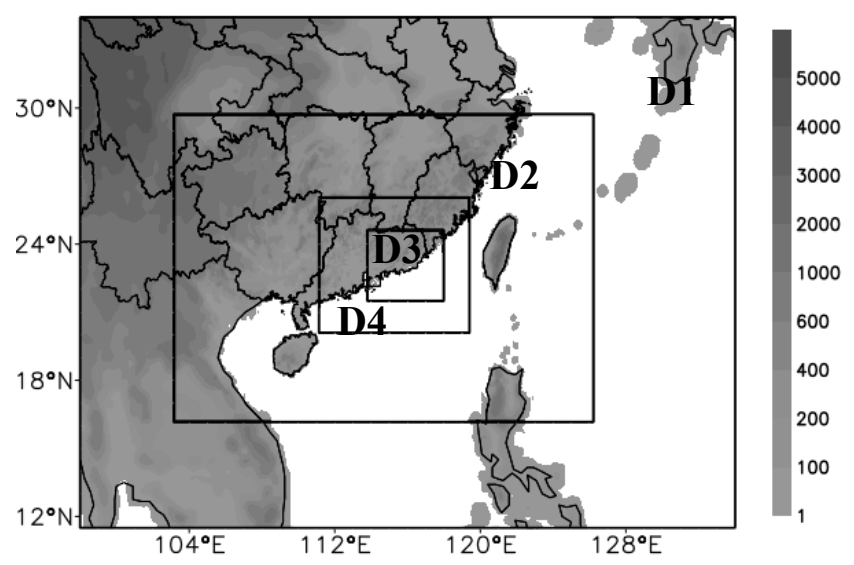

Figure 4. Model domains (D1-D4); the shading indicates the topography.

\section{Results}

\subsection{Synoptic Evolution Comparison}

The synoptic environments were examined using the European Centre for Medium-Range Weather Forecasts Reanalysis interim Data (ERA-interim) $\left(0.125^{\circ} \times 0.125^{\circ}\right)$ and the corresponding simulation results. Figure 5 shows the distribution of the potential pseudo-equivalent temperature, horizontal winds, and geopotential height at $850 \mathrm{hPa}$. The simulation results in Figure $5 \mathrm{~b}, \mathrm{~d}$ are consistent with the analysis fields in Figure 5a,c. Figure 5 also illustrates that a low-pressure center existed over the eastern Tibetan Plateau. South China was located at the head of a trough with a warm, wet tongue and prevailing southwesterly wind, and the potential pseudo-equivalent temperature reached more than $356 \mathrm{~K}$ over Guangdong, where the magnitude was larger before the torrential rains occurred at 1800 UTC on 19 May 2015. Unlike the warm sector severe weather that forms in parts of the Great Plains of America [9], there are no apparent high-level synoptic systems (e.g., $300 \mathrm{hPa}$ jets) during the torrential rains over South China. Tochimoto and Niino [32] summarized the composite structural and environmental characteristics of tornado outbreaks in the warm sector and showed that the low-level environment plays an important role in the formation of a tornado. In this paper, we focus on the low-level characteristics and the ability of the PBL parameterization in numerical simulations to model WSTRs over southern China.

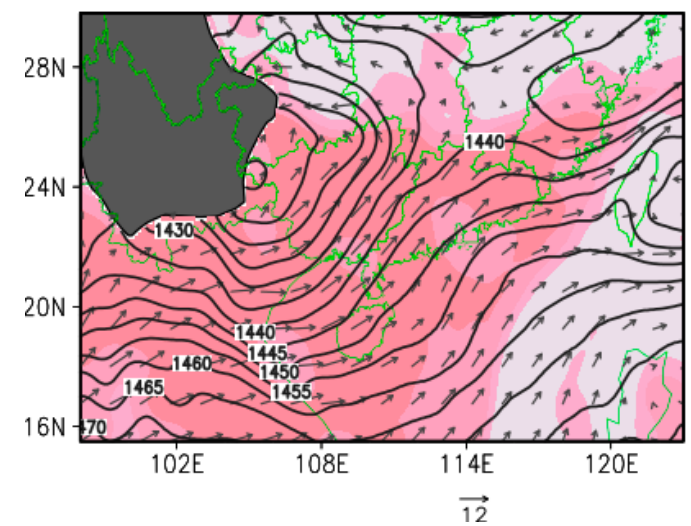

(a)

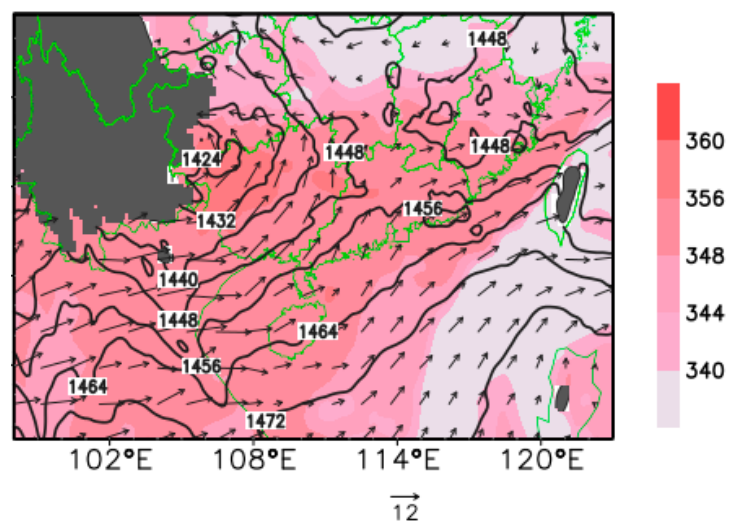

(b)

Figure 5. Cont. 


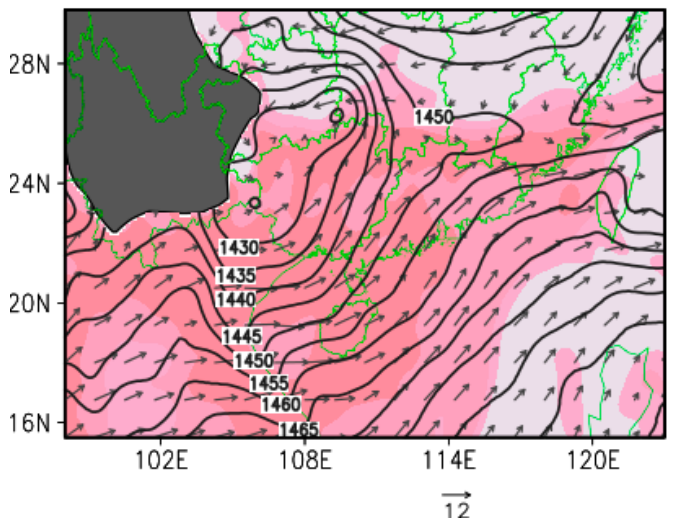

(c)

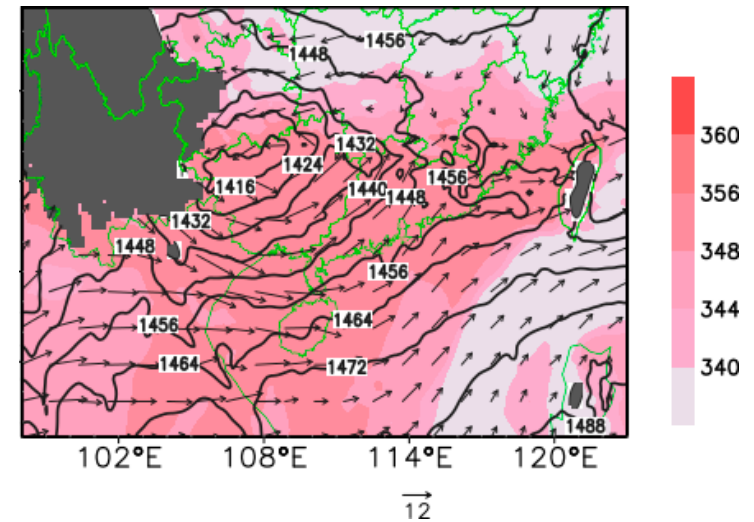

(d)

Figure 5. Comparison of the potential pseudo-equivalent temperature (shaded, K), horizontal wind, and geopotential height at $850 \mathrm{hPa}$ (contours, $10 \mathrm{gpm}$ ) of (a,c) the ERA interim analysis data and (b,d) the D1 simulation results at $850 \mathrm{hPa}$ at (a,b) 1800 UTC on 19 May and (c,d) 0000 UTC on 20 May 2015; the shaded region in gray indicates topography.

Figure 6 shows the 24-h accumulated rainfall at 1200 UTC on 20 May using the TEMF PBL scheme. It can be seen that the magnitude and distribution of the precipitation were successfully captured by the TEMF scheme, with a slightly underestimation on the magnitude of the precipitation. The simulation of the strong precipitation center reached more than $300 \mathrm{~mm}$ with a reasonable simulation of the distribution of the rain belt, as well as a good simulation of the rainfall over Northwest Shanwei.

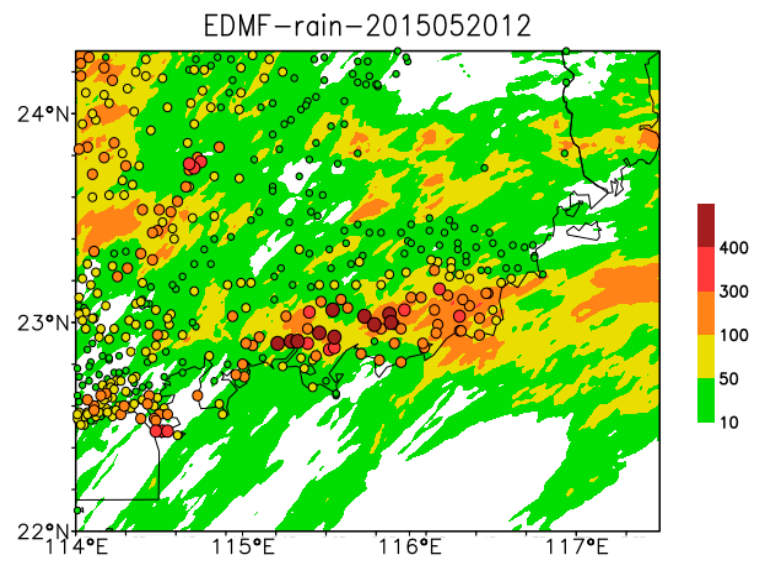

Figure 6. The 24-h accumulated rainfall from the D4 simulation for 1200 UTC 19 May-1200 UTC 20 May 2015, using the TEMF scheme. The shading represents the simulation results, the dots denote the observations, and the magnitudes of the simulation and the observation share the same color bar.

\subsection{The Extra LLJ and Unstable Stratification}

The low-level circulation and environment were examined in Figure 7. We can see that there was an extra LLJ flow over the Beibu Gulf and South China Sea (SCS), forming the atmospheric moisture transportation (AMT) over South China Sea. This moisture transportation, characterized by its high $\theta_{s e}$ (greater than $350 \mathrm{~K}$ ) and abundant moisture, gathered moisture from the Beibu Gulf and SCS and brought abundant moisture and convective energy into Shanwei. The evolution of the AMT was consistent with the occurrence of the torrential rains, which occurred near 0000 UTC on 20 May. After the AMT moved into the SCS, the magnitude of the precipitation weakened substantially. 
A vertical cross section along the $114^{\circ} \mathrm{E}$ longitude was taken to analyze the stability of the layers in the AMT. Figure 8 demonstrates that $\theta_{s e}$ decreased with height within the layers below $600 \mathrm{hPa}$ $\left(\frac{d \theta_{s e}}{d p}>0\right)$, indicating that these layers were convectively unstable. In addition, the large values of the vertical gradient of $\theta_{\text {se }}$ were primarily concentrated below $900 \mathrm{hPa}$ with a continuous southerly wind in the AMT, where the value of $\theta_{\text {se }}$ reached more than $350 \mathrm{~K}$. Weak upward flow turned to strong convective upward flow at 0000 UTC on 20 May over adjacent areas of land and sea with a corresponding explosive growth in $\theta_{\text {se }}$. Ascending vertical motion was triggered via orographic lift effects, especially at 0200 UTC on 20 May (Figure 8c). The orographic effects also resulted in a displacement of the thermal ridge $(350 \mathrm{~K})$, which was similar to the synoptic forcing on the PBL by the large-scale flow [10], and contributed to the severe rainfall center over Haifeng (Figure 6).

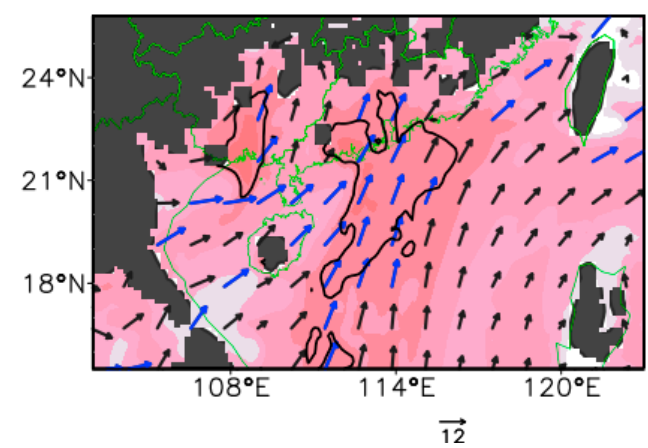

(a)

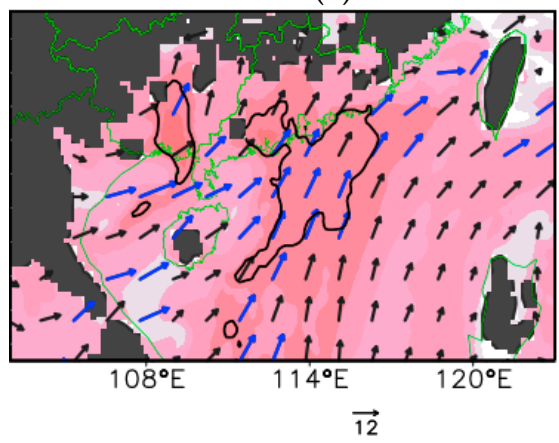

(c)

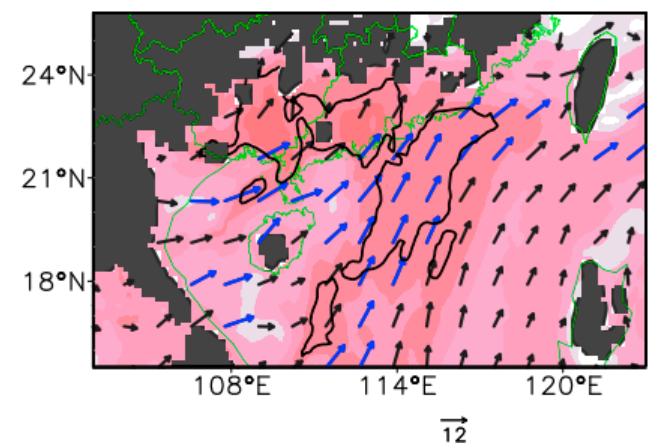

(b)

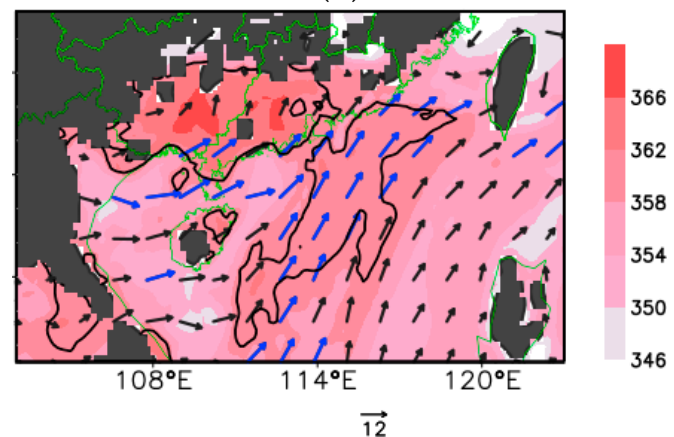

(d)

Figure 7. Potential pseudo-equivalent temperature $\left(\theta_{\text {se }}\right.$, shaded every $4 \mathrm{~K}$; the thick solid lines denote the distribution at $350 \mathrm{~K}$ ) and horizontal wind from the D1 simulation at $950 \mathrm{hPa}$ (the blue bars denote wind speed exceeding $12 \mathrm{~ms}^{-1}$ ) valid at (a) 2200 UTC on 19 May and at (b) 0000, (c) 0200, and (d) 0400 UTC on 20 May; the shaded regions in gray indicate the topography.

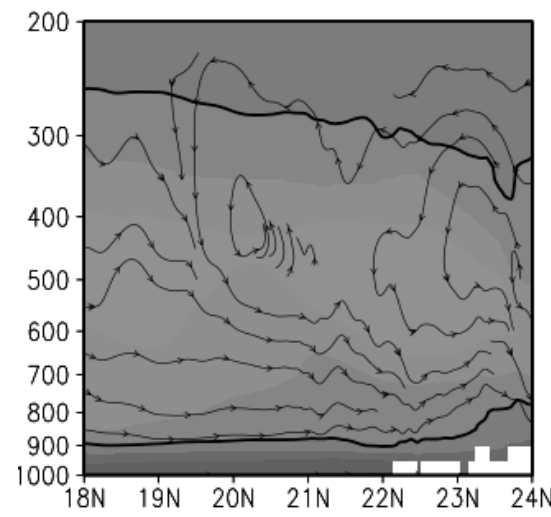

(a)

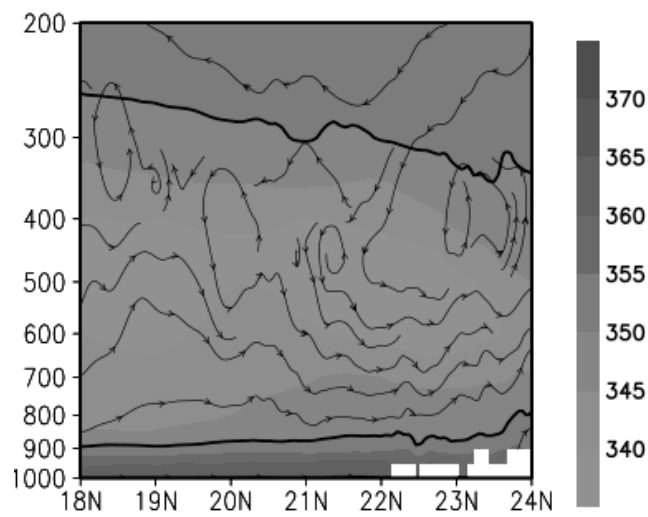

(b)

Figure 8. Cont. 


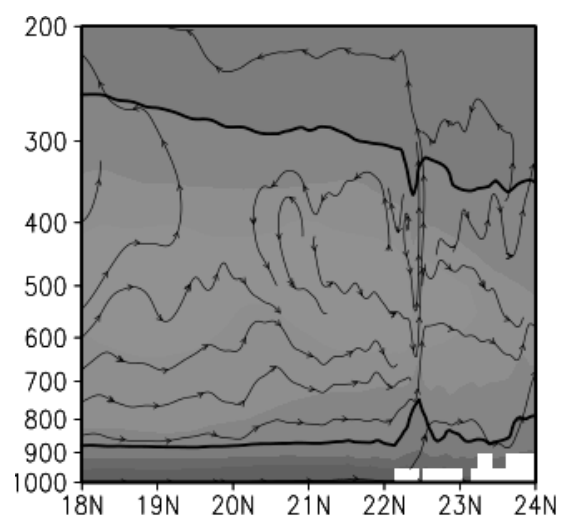

(c)

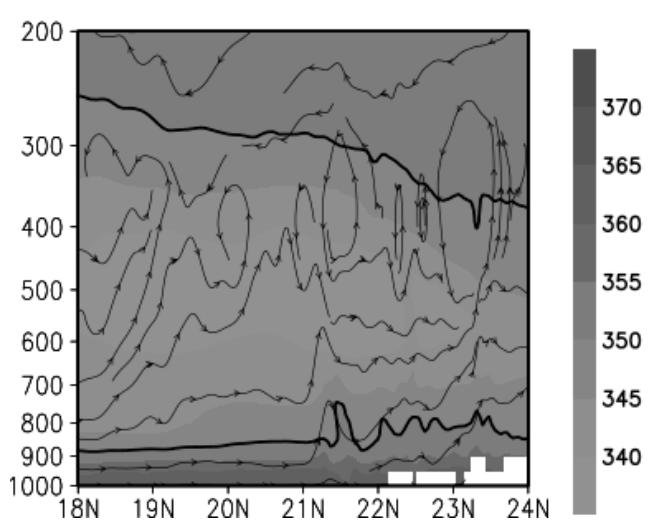

(d)

Figure 8. Vertical cross section corresponds to $114 \mathrm{E}$ of $\theta_{s e}$ (shaded every $5 \mathrm{~K}$; the thick solid lines denote the distribution at $350 \mathrm{~K}$ ) and the meridional wind from the D2 simulation valid at (a) 2000 and (b) 2200 UTC on 19 May and (c) 0000 and (d) 0200 UTC on 20 May.

To further investigate the characteristics of the AMT, the vertical integrated water vapor flux (IWF) and the humidity were analyzed in Figure 9. Considerable moisture can be seen in the northeast transport below $800 \mathrm{hPa}$ along the AMT; this transport supplied abundant water vapor for the convection in the WSTR. The magnitude of the IWF below $800 \mathrm{hPa}$ reached a remarkable $600 \mathrm{~kg} \cdot \mathrm{m}^{-1} \cdot \mathrm{s}^{-1}$. Conversely, the free troposphere exhibited a relatively dry environment above $800 \mathrm{hPa}$ over the SCS. The AMT band transport of moisture to the coastal region in southern Guangdong may result from the horizontal transport from lower latitudes and vertical transport with an enhanced southwesterly low-level flow, as suggested by [33]. This AMT may also be related to typical characteristics such as the onset of the Asian summer monsoon over the SCS [34].

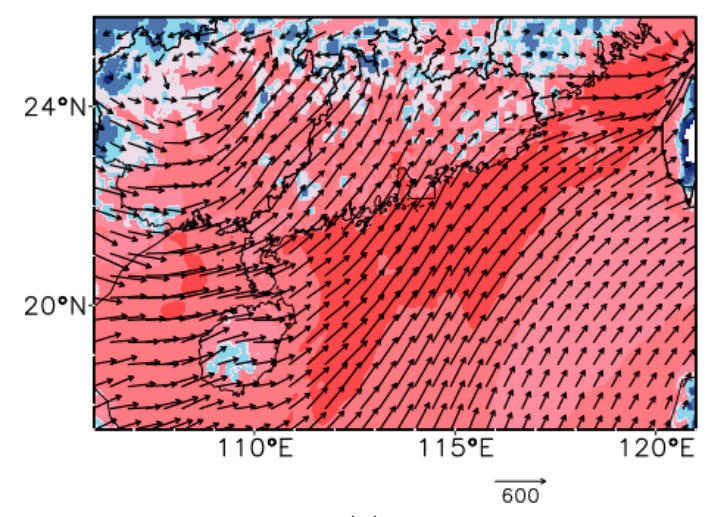

(a)

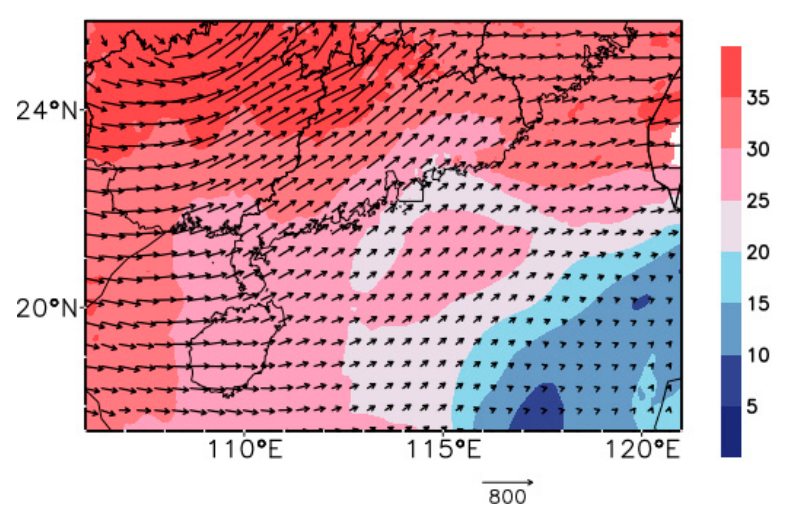

(b)

Figure 9. Vertically integrated humidity (shading; $\mathrm{mm}$ ) and water vapor flux (vectors; $\mathrm{kgm}^{-1} \mathrm{~s}^{-1}$ ) (a) below $800 \mathrm{hPa}$ and (b) above $800 \mathrm{hPa}$ from the D2 simulation at 0000 UTC on 20 May 2015.

Owing to the lack of sounding observation data over Shanwei, the sounding data of an adjacent station in Hong Kong are used in this paper. Figure 10 shows that the convective available potential energy (CAPE) was very high at both 1200 UTC on 19 May and 0000 UTC on 20 May, reaching values of 2259 and $3321 \mathrm{~J} \cdot \mathrm{kg}^{-1}$, respectively. The corresponding lifted condensation pressures were 929 and $935 \mathrm{hPa}$, respectively, and the precipitable water reached $60 \mathrm{~mm}$, which means that the instability and water vapor in the environment were both favorable for convection. The low-level wind was consistent with the southwesterly wind, with a horizontal wind speed of $12 \mathrm{~m} \cdot \mathrm{s}^{-1}$ at $952 \mathrm{hPa}$ at $1800 \mathrm{UTC}$ on 19 May. The simulation results confirmed the observational data, e.g., the simulated CAPE at 1200 UTC on 19 May and at 0000 UTC on 20 May were 2555 and $3293 \mathrm{~J} \cdot \mathrm{kg}^{-1}$, respectively, and the simulated 
precipitable water was $60 \mathrm{~mm}$. Figure 11 show the simulated vertical profiles of the skew at Haifeng. It can be seen that the CAPE was 1294 and $1064 \mathrm{~J} \cdot \mathrm{kg}^{-1}$ at $1200 \mathrm{UTC}$ on 19 May and at 0000 UTC on 20 May, respectively. Note that the precipitable water reached $70 \mathrm{~mm}$, and the corresponding lifted condensation pressures were 972 and $954 \mathrm{hPa}$, respectively. Moreover, the dew temperature was very close to the temperature below $500 \mathrm{hPa}$, and the wind shear was relatively small. The skew pattern has been stressed in local weather forecasting manuals by both Lin [3] and Sun [35]; however, the altitude of the LLJ in this paper (950 hPa) was lower than that found by Lin [3] (i.e., 850-700 hPa).

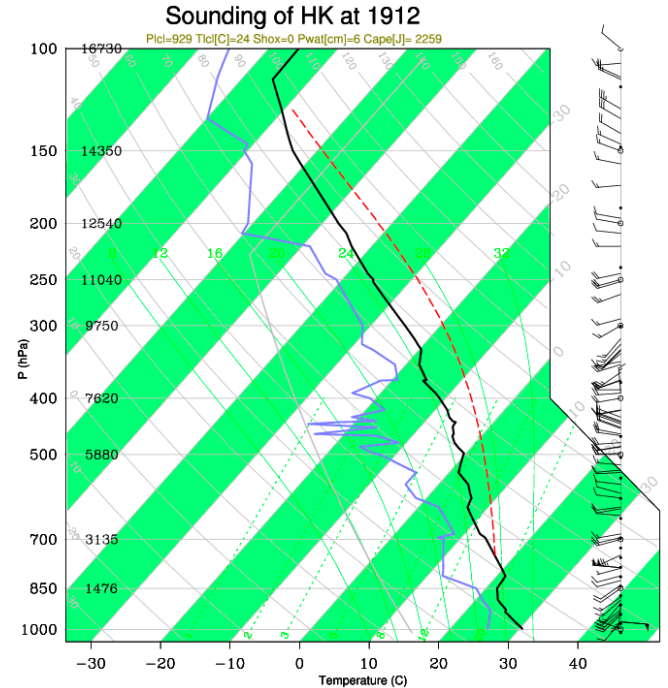

(a)

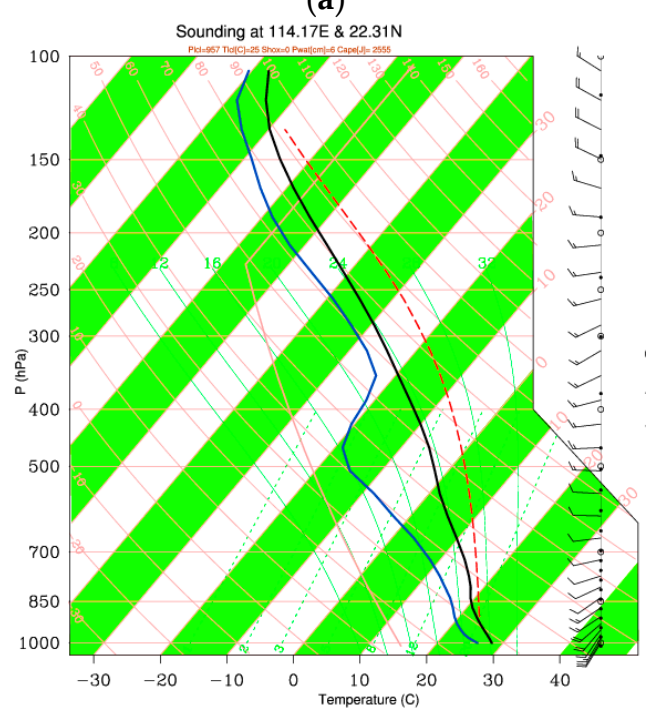

(c)

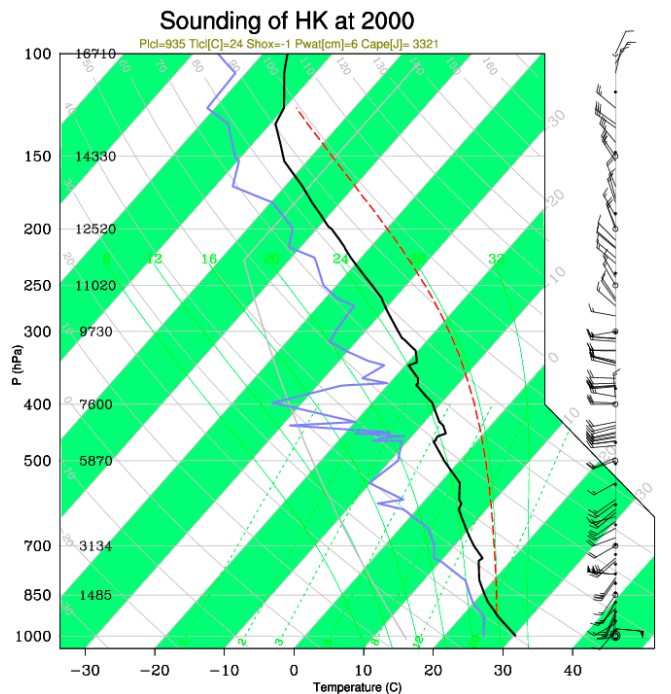

(b)

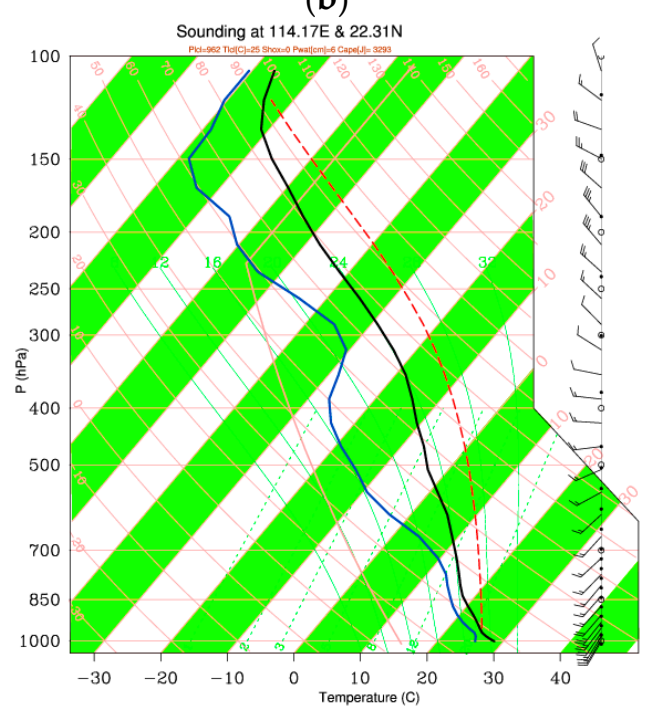

(d)

Figure 10. Comparison of the vertical profiles of skew on a T-log P diagram of the temperature (black line), dew point temperature (blue line), and ascending curve of a near surface air parcel (green line) over the Hong Kong sounding for $(\mathbf{a}, \mathbf{b})$ the observation and $(\mathbf{c}, \mathbf{d})$ the D4 simulation at $(\mathbf{a}, \mathbf{c}) 1200$ UTC on 19 May and at $(\mathbf{b}, \mathbf{d}) 0000$ UTC on 20 May. 


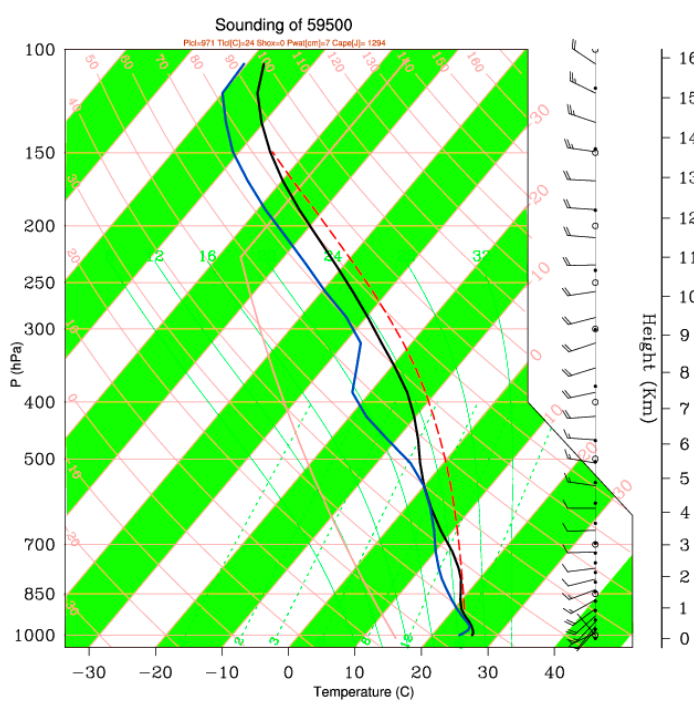

(a)

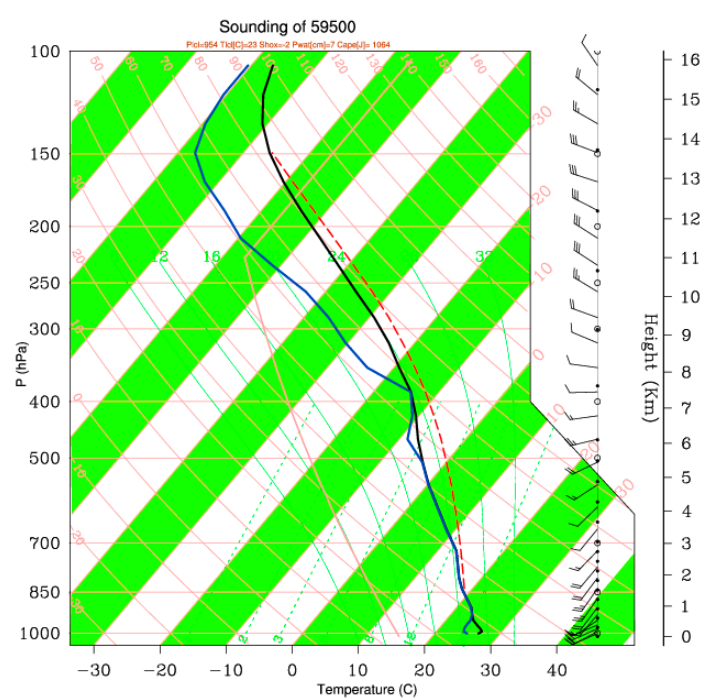

(b)

Figure 11. As in Figure 10 but showing the simulated results for Haifeng At (a) 1200 UTC on 19 May and (b) 0000 UTC on 20 May.

\subsection{ERA Interim Data Verification}

The ERA interim daily fields and synoptic monthly means of the sea surface temperature (SST) and the wind data reveal that the average SST over the SCS remained warm in May and reached more than $30^{\circ} \mathrm{C}$ over most parts of the SCS (Figure 12). There was also a maximum high wind speed center over the SCS, which exceeded $6 \mathrm{~m} \cdot \mathrm{s}^{-1}$ at its center according to monthly means of the $10 \mathrm{~m}$ wind speed, as well as a maximum high wind speed center greater than $10 \mathrm{~m} \mathrm{~s}^{-1}$ according to the 10 day mean in late May at $950 \mathrm{hPa}$.

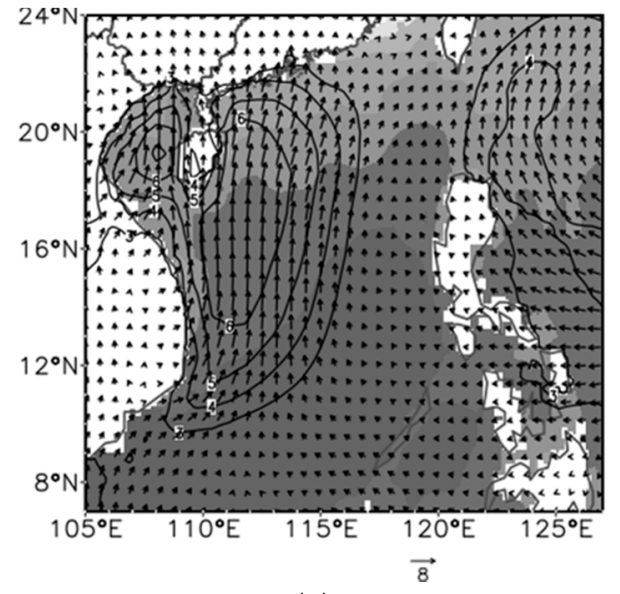

(a)

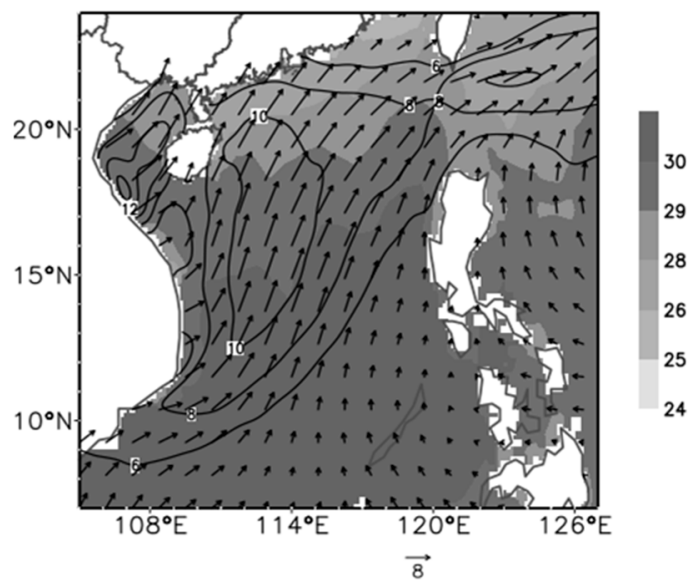

(b)

Figure 12. (a) ERA interim fields of the synoptic monthly means of the sea surface temperature (shaded, ${ }^{\circ} \mathrm{C}$ ), $10 \mathrm{~m}$ wind speed (contour, $\mathrm{ms}^{-1}$ ), and wind barbs of May 2015. (b) ERA interim daily fields at 0000 UTC in late May (from 20 May to 30 May) of the sea surface temperature (shaded, ${ }^{\circ} \mathrm{C}$ ), horizontal wind speed (contour, $\mathrm{ms}^{-1}$ ), and wind barbs at $950 \mathrm{hPa}$.

Four torrential rain cases were chosen to analyze the parameters within the PBL using the Hong Kong sounding during the WSTRs in May for each year from 2013 to 2016. Every case was characterized by a strong LLJ within the PBL, a large CAPE, and strong precipitation water (PW) for the entire 
sounding, e.g., the WSTR torrential rains of 11 and 12 May 2014, which caused the most severe flood in Shenzhen since 2008; its maximum wind speed (MWS) reached $22.1 \mathrm{~m} \cdot \mathrm{s}^{-1}$ at $925 \mathrm{hPa}$, with a CAPE of $1471.9 \mathrm{~J} \cdot \mathrm{kg}^{-1}$ and a PW of $66.2 \mathrm{~mm}$. The LLJ was extremely strong in the early morning of 11 May 2014 (Figure 14), with a strong southwesterly wind over the SCS, where the AMT was formed by two flows from the SCS and the Beibu Gulf.

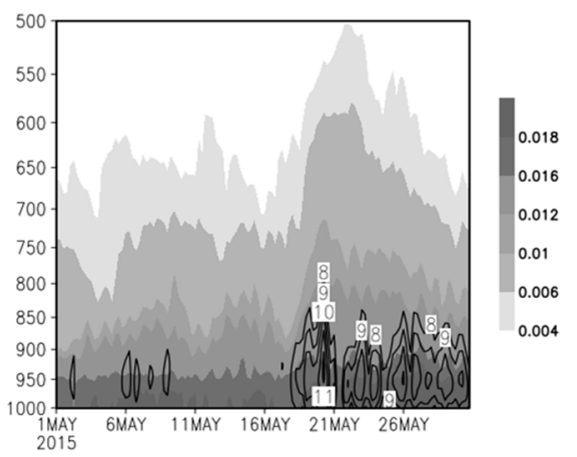

(a)

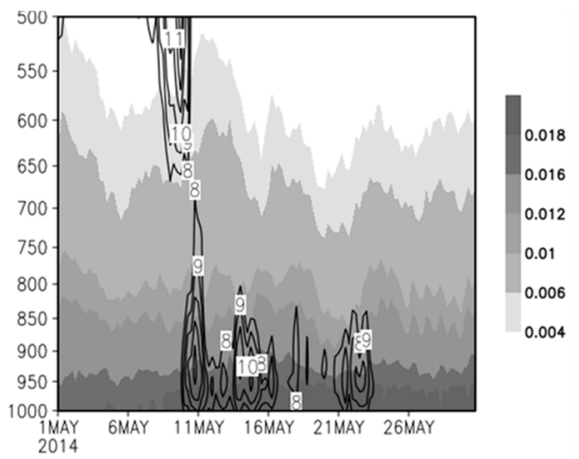

(b)

Figure 13. ERA interim daily fields of the time series of the wind speed $\left(\mathrm{ms}^{-1}\right)$ and specific humidity (shaded, $\mathrm{gkg}^{-1}$ ) below $500 \mathrm{hPa}$ in May of (a) 2015 and (b) 2014 from the averaged area over the SCS shown in Figure 14.

In general, the WSTRs over South China are strongly related to the moisture transportation over the SCS. The analysis on the atmospheric moisture transport of the cases in 2014 and 2015 are discussed in this paper. Time series of the wind speed and specific humidity below $500 \mathrm{hPa}$ indicated that the two WSTRs in May of 2014 and 2015 were consistent with outbreaks of strong wind below $850 \mathrm{hPa}$ (Figure 13). The wind speed within the PBL reached more than $12 \mathrm{~m} \mathrm{~s}^{-1}$ during the outbreak period, and the majority of SCS monsoons begin during or near these days (e.g., 20 May in 2015).

A final simulation for 2014 was performed, where the same schemes were used. The results are similar to those obtained for 2015 (Figure 15), except that there is no apparent high $\theta_{s e}$ tongue stretching to the coastal regions over southern China, which would likely have caused a lower CAPE (Table 1) and smaller amounts of precipitation, indicating that the thermal effects of the AMT are crucial to the magnitude of the WSTR precipitation over South China.

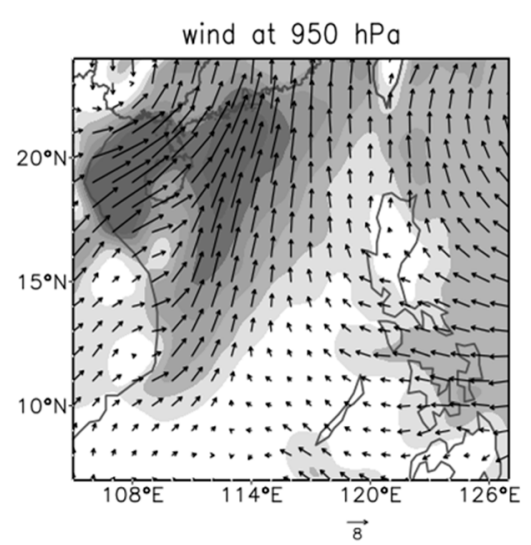

(a)

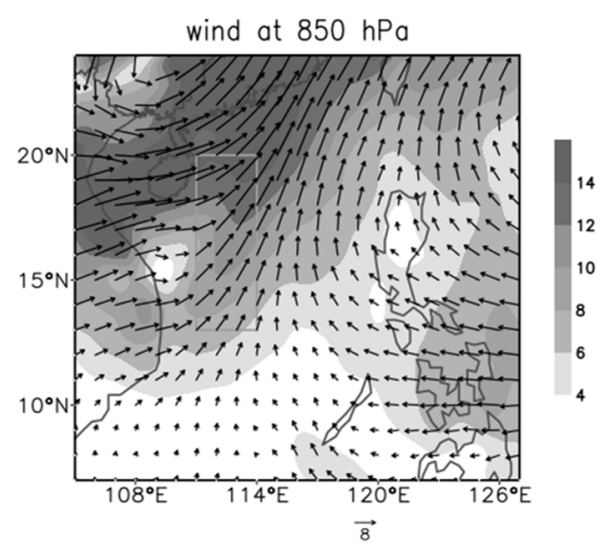

(b)

Figure 14. ERA interim daily fields of the horizontal wind speed (shaded, $\mathrm{ms}^{-1}$ ) and wind barbs at (a) $950 \mathrm{hPa}$ and (b) $850 \mathrm{hPa}$ at $0000 \mathrm{UTC}$ on 11 May 2014; the green rectangle denotes the area illustrated in Figure 13. 
Table 1. Parameters within the PBL according to the Hong Kong sounding during the WSTR in May from 2013 to 2016. MWS denotes the maximum wind speed, and LEV represents the corresponding level, whereas PW denotes the precipitation water for the entire sounding.

\begin{tabular}{ccccc}
\hline Case & MWS $\left(\mathbf{m ~ s}^{-\mathbf{1}}\right)$ & LEV (hPa) & CAPE (J kg $\left.\mathbf{~}^{-\mathbf{1}}\right)$ & PW (mm) \\
\hline $20130521-22$ & 16.9 & 850 & 2978.8 & 69.9 \\
$20140511-12$ & 22.1 & 925 & 1471.9 & 66.2 \\
$20150520-21$ & 15.9 & 942 & 2547.1 & 71.9 \\
$20160520-21$ & 15.9 & 887 & 827.9 & 66.9 \\
\hline
\end{tabular}

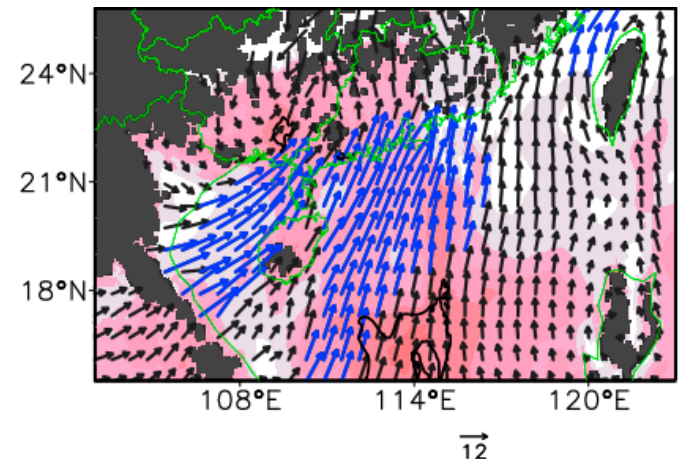

(a)

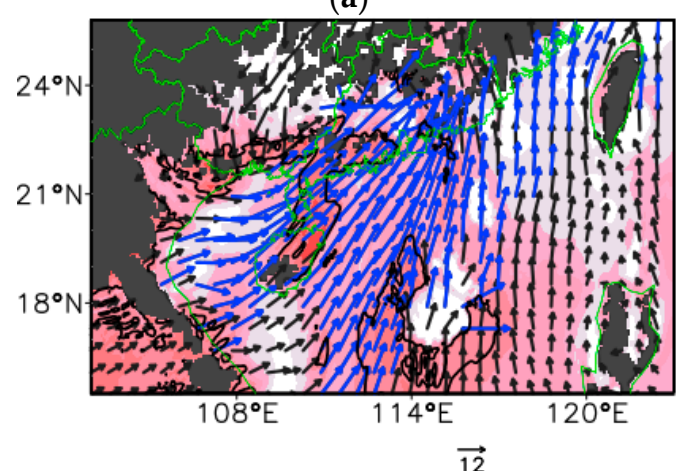

(c)

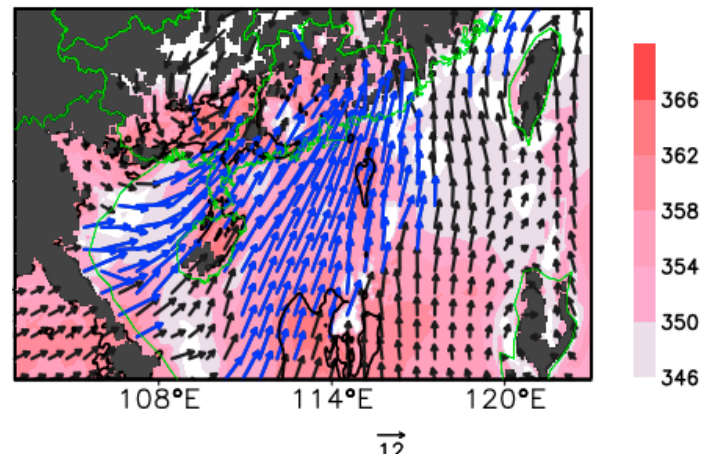

(b)

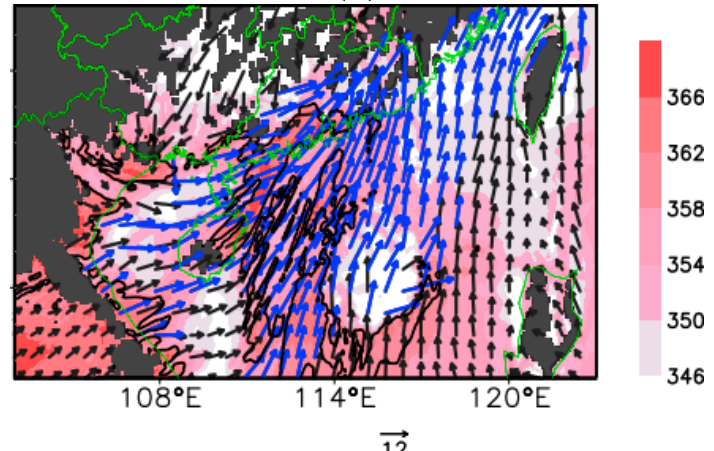

(d)

Figure 15. As in Figure 7 but for 2-h intervals from 0200 UTC to 0800 UTC on 11 May 2014. (a) 0200; (b) 0400; (c) 0600 and (d) 0800.

\section{Discussion and Conclusions}

This paper investigated a warm sector extreme precipitation event that occurred in Guangdong on 20 May 2015. An intercomparison of two PBL parameterizations in the WRF model was presented, and the TEMF scheme was evaluated in terms of the synoptic patterns within the PBL and the vertical profiles of WSTR cases, as well as a diagnostic verification using ERA interim data and Hong Kong sounding data. It was shown that the extreme precipitation, characterized by its rapid development, high concentration, and long duration of heavy rainfall, occurred over the trumpet-shaped topography of Haifeng, with Lianhua Mountain in the northwest and Emei Zhang Mountain in the north. Simulation results indicated that the AMT is essential in triggering the precipitation of the WSTR over South China. In addition, the simulation of the WSTR was extremely sensitive to the PBL schemes over South China, whereas the TEMF scheme provided a better estimation of the precipitation. Via the diagnostic analysis and simulation experiments, this study led to several key conclusions:

(1) Simulations of the WSTR over South China are very sensitive to the PBL scheme. Even though both the TEMF and Yonsei University (YSU) schemes provided a fine simulation of the AMT and the precipitation, the TEMF scheme provided a reasonable simulation of the circulation and the 
vertical profile in the PBL, as well as a better estimation of the precipitation, whereas the YSU scheme underestimated the precipitation and the AMT values.

(2) The AMT, extending from the Beibu Gulf and the South China Sea to the coastal areas and providing Shanwei with considerable amounts of moisture in the boundary layer, was one of the important large-scale factors causing the WSTR.

(3) Effects within the PBL had a large impact on the formation of the WSTR, especially the orographic effects and the extra LLJ in the boundary layer, as well as the high-energy tongue characterized by a high-potential pseudo-equivalent temperature tongue with a warm and moist southwesterly wind.

(4) In summary, the AMT and PBL processes, including the orographic effects and the high-energy tongue, caused the WSTR event in 2015. Note that the convection may be related to shallow convection and that the TEMF scheme provided a better simulation, primarily because the TEMF scheme could produce superior depictions of the vertical thermodynamic structure. Recognizing that just two cases cannot provide a rigorous test of the multiscale characteristics in the WSTR, it is difficult to discuss the triggering mechanism of the torrential rains. Despite its underestimation of the precipitation, the TEMF scheme simulates the AMT and produces more realistic distributions and magnitudes of the rainfall than do other schemes. Further sensitive experiments and statistical analyses are planned to investigate the PBL effects on extreme precipitation events in the WSTR.

Acknowledgments: This study was supported by the National Natural Science Foundation of China (41505084, 41275053, 41461164006), China Meteorological Administration Special Public Welfare Research Fund (GYHY201406003, GYHY201406013), Guangdong Meteorological Service Project (2015B01). Guangdong province public welfare research and capacity construction project (2017B020218003).

Author Contributions: Shuixin Zhong and Zitong Chen designed and performed the experiments; Shuixin Zhong analyzed the data and wrote the paper.

Conflicts of Interest: The authors declare no conflict of interest.

\section{References}

1. Huang, S.S. Rainstorms in Pre-Rainny Season over South China; Guangdong Science Press: Guangzhou, China, 1986; pp. 108-120.

2. Tao, S.Y. Rainstorms in China; Chinese Science Press: Beijing, China, 1980; p. 13.

3. Lin, L.X. Technical Manuals of the Weather Forecasting in Guangdong Province; Chinese Meteorological Press: Beijing, China, 2006; p. 7.

4. Maddox, R.A.; Chappell, C.F.; Hoxit, L.R. Synoptic and meso-scale aspects of flash flood events. Bull Am. Meteorol. Soc. 1979, 60, 115-123. [CrossRef]

5. Xu, W.; Zipser, E.J.; Chen, Y.L.; Liu, C.; Liou, Y.C.; Lee, W.C.; Jong-Dao, J.B. An orography-associated extreme rainfallevent during TiMREX: Initiation, storm evolution, and maintenance. Mon. Weather Rev. 2012, 140, 2555-2574. [CrossRef]

6. Wang, C.C.; Hsu, C.S.; Chen, J.T.J.; Lee, D.I. A study of two propagating heavy-rainfall episodes near Taiwan during SoWMEX/TiMREX IOP-8 in June 2008. Part I: Synoptic evolution, episode propagation, and model control simulation. Mon. Weather Rev. 2014, 142, 2619-2643. [CrossRef]

7. Schumacher, R.S.; Johnson, R.H.; Johnson, R.H. Quasi-stationary, extreme-rain-producing convective systems associated with midlevel cyclonic circulations. Weather Forecast. 2009, 24, 555-574. [CrossRef]

8. Lai, H.W.; Davis, C.A.; Jou, B.J.D. A subtropical oceanic mesoscale convective vortex observed during SoWMEX/TiMREX. Mon. Weather Rev. 2011, 139, 2367-2385. [CrossRef]

9. Boustead, J.M.; Mayes, B.E.; Gargan, W.; Leighton, J.L.; Phillips, G.; Schumacher, P.N. Discriminating environmental conditions for significant warm sector and boundary tornadoes in parts of the Great Plains. Weather Forecast. 2013, 28, 1498-1523. [CrossRef]

10. Lieman, R.; Alpert, P. Investigation of the planetary boundary layer height variations over complex terrain. Bound. Layer Meteorol. 1993, 62, 129-142. [CrossRef] 
11. Wang, H.; Luo, Y.; Jou, B.J.D. Initiation, maintenance, and properties of convection in an extreme rainfall event during SCMREX: Observational analysis. J. Geophys. Res. 2014, 119. [CrossRef]

12. Tu, C.C.; Chen, Y.L.; Chen, C.S.; Lin, P.L.; Lin, P.H. A comparison of two heavy rainfall events during the Terrain-Influenced Monsoon Rainfall Experiment (TiMREX) 2008. Mon. Weather Rev. 2014, 142, 2436-2463. [CrossRef]

13. Huang, H.Y.; Hall, A.; Teixeira, J. Evaluation of the WRF PBL parametrizations for marine boundary layer clouds: Cumulus and stratocumulus. Mon. Weather Rev. 2013, 141, 2265-2271. [CrossRef]

14. Banks, R.F.; Tiana-Alsina, J.; Rocadenbosch, F.; Baldasano, J.M. Performance Evaluation of the Boundary-Layer Height from Lidar and the Weather Research and Forecasting Model at an Urban Coastal Site in the North-East Iberian Peninsula. Bound. Layer Meteorol. 2015, 157, 265-292. [CrossRef]

15. Dimetrova, R.; Silver, Z.; Zsedrovits, T.; Hocut, C.M.; Leo, L.S.; DiSabatino, S.; Fernando, H.J.S. Assessment of Planetary Boundary-Layer Schemes in the Weather Research and Forecasting Mesoscale Model Using MATERHORN Field Data. Bound. Layer Meteorol. 2016, 159, 589. [CrossRef]

16. Cohen, A.E.; Steven, M.S.; Coniglio, M.C.; Brooks, H.E. A review of planetary boundary Layer parametrization schemes and their sensitivity in simulating southeastern U.S. cold season severe weather environments. Weather Forecast. 2015, 30, 591-612. [CrossRef]

17. Mielikainen, J.; Bormin, H.; Huang, H.L.A. Optimizing Total Energy-Mass Flux (TEMF) planetary boundary layer scheme for intel's many integrated core (MIC) architecture. J. Sel. Top. Appl. Earth Obs. Remote Sens. 2015, 8, 4106-4119. [CrossRef]

18. Gimeno, L.; Stohl, A.; Trigo, R.M.; Dominguez, F.; Yoshimura, K.; Yu, L.; Drumond, A.; Durán-Quesada, A.M.; Nieto, R. Oceanic and terrestrial sources of continental precipitation. Rev. Geophys. 2012, 50, RG4003. [CrossRef]

19. Drumond, A.; Nieto, R.; Gimeno, L. Sources of moisture for China andtheir variations during drier and wetter conditions in 2000-2004: A Lagrangianapproach. Clim. Res. 2011, 50, 215-225. [CrossRef]

20. Stensrud, D.J. Importance of low-level jets to climate: A review. J. Clim. 1996, 9, 1698-1711. [CrossRef]

21. Higgins, R.W.; Mo, K.C.; Schubert, S.D. The moisture budget of the central United States in spring as evaluated in the NCEP-NCAR and the NASA-DAO reanalyses. Mon. Weather. Rev. 1996, 124, 939-963. [CrossRef]

22. Higgins, R.W.; Yao, Y.; Yarosh, E.S.; Janowiak, J.E.; Mo, K.C. Influence of the Great Plains low-level jet on summertime precipitation and moisture transport over the central United States. J. Clim. 1997, 10, 481-507. [CrossRef]

23. Skamarock, W.C.; Klemp, J.B.; Dudhia, J.; Gill, D.O.; Barker, D.M.; Duda, M.G.; Powers, J.G. A Description of the Advanced Research WRF Version 3; Tech. Rep. NCAR Technical Note, NCAR/TN-475+STR; Mesoscale and Microscale Meteorology Division, National Center for Atmospheric Research: Boulder, CO, USA, 2008; p. 125.

24. Dudhia, J. Numerical study of convection observed during the Winter Monsoon Experiment using a mesoscale two-dimensional model. J. Atmos. Sci. 1989, 46, 3077-3107. [CrossRef]

25. Mlawer, E.J.; Taubman, S.J.; Brown, P.D.; Iacono, M.J.; Clough, S.A. Radiative transfer for inhomogeneous atmospheres: RRTM, a validated correlated-k model for the longwave. J. Geophys. Res. 1997, 102, 16663-16682. [CrossRef]

26. Hong, S.Y.; Lim, J.O.J. The WRF single-moment 6-class microphysics scheme (WSM6). J. Korean Meteorol. Soc. 2006, 42, 129-151.

27. Fritsch, J.M.; Kain, J.S. Convective parametrization for mesoscale models: The Fritsch-Chappell scheme. Meteorol. Monographs 1993, 46, 165-170.

28. Kain, J.S. The Kain-Fritsch convective parametrization: An update. J. Appl. Meteorol. 2004, 43, $170-181$. [CrossRef]

29. Angevine, W.M.; Jiang, H.L.; Mauritsen, T. Performance of an eddy diffusivity-mass flux scheme for shallow cumulus boundary layers. Mon. Weather Rev. 2010, 138, 2895-2912. [CrossRef]

30. Siebesma, A.P.; Soares, P.M.; Teixeira, J. A combined eddy-diffusivity mass-flux approach for the convective boundary layer. J. Atmos. Sci. 2007, 64, 1230-1248. [CrossRef]

31. Angevine, W.M.; Baltink, H.K.; Bosveld, F.C. Observations of the morning transition of the convective boundary layer. Bound. Layer Meteorol. 2001, 101, 209-227. [CrossRef] 
32. Tochimoto, E.; Niino, H. Structural and environmental characteristics of extratropical cyclones that cause tornado outbreaks in the warm sector: A composite study. Mon. Weather Rev. 2016. [CrossRef]

33. Bao, J.W.; Michelson, S.A.; Neiman, P.J.; Ralph, F.M.; Wilczak, J.M. Interpretation of enhanced integrated water vapor bands associated with extratropical cyclones: Their formation and connection to tropical moisture. Mon. Weather Rev. 2006, 134, 1063-1080. [CrossRef]

34. Chang, C.P.; Chen, G.T.J. Tropical circulations associated with southwest Monsoon onset and westerly surges over the South China Sea. Mon. Weather Rev. 1995, 123, 3254-3267. [CrossRef]

35. Sun, J.S. Basic Principles and Technology on the Forecasting of the Strong Convection; Chinese Meteorological Press: Beijing, China, 2014; p. 101.

2017 by the authors. Licensee MDPI, Basel, Switzerland. This article is an open access article distributed under the terms and conditions of the Creative Commons Attribution (CC BY) license (http://creativecommons.org/licenses/by/4.0/). 